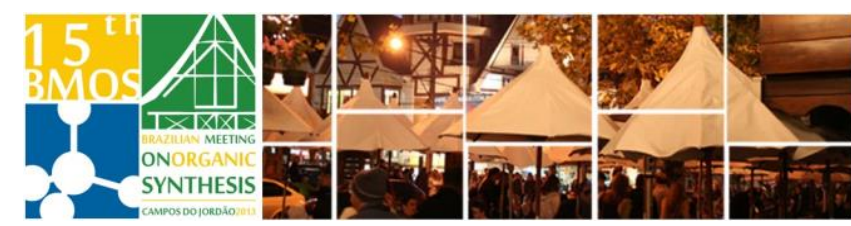

\title{
Synthesis of Quinoline-Triazoil Carboxylates by Organocatalytic Cycloaddition of $\beta$-Ketoesters and 4-Azido-7-Chloroquinoline
}

\author{
* Maiara Saraiva, Roberta Krüger, Diego Alves \\ Laboratório de Síntese Orgânica Limpa - LASOL, Universidade Federal de Pelotas, UFPel, Pelotas, RS, \\ Brasil. \\ * maiara.torchelsen@gmail.com
}

Keywords: Organocatalysis, Triazoles, Quinolines.

\section{INTRODUCTION}

The importance of heterocyclic compounds is indisputable, especially the 1,2,3-triazoles, which have attracted much interest because they have a wide field of applications, ranging from use as explosives, even pesticides and as drugs. ${ }^{1}$ However recent discoveries of methodologies for obtaining functionalized 1,2,3-triazoles, the interest on this class of compounds is increasing, and, among these methods of synthesis, there is the organocatalytic enamide-azide cycloaddition reaction. ${ }^{2}$

Similarly, another class of widely studied heterocycles are quinolines, which are characterized by containing in their structure a benzene ring fused to a pyridinic ring. ${ }^{3}$ The interest in the synthesis of quinoline derivatives also has been increased for their know pharmacological properties. ${ }^{4}$

Because of the importance related to these two classes of heterocyclic compounds and due to potential biological applicability, we describe here or results on the synthesis of quinoline-triazoil carboxylates 3 through organocatalytic enamideazide cycloaddition reaction between $\beta$-Ketoesters 1 and 4-Azido-7-Chloroquinoline 2.

\section{RESULTS AND DISCUSSION}

Initially, studies were conducted to determine the best reaction condition. For this, was reacted the ethylacetoacetate 1a with 4-Azido-7-Chloroquinoline 2 and various organocatalysts, such as, pyrrolidine, piperidine, L-Proline, Et ${ }_{2} \mathrm{NH}$, Et ${ }_{3} \mathrm{~N}$, using DMSO as solvent at different concentrations.

Figure 1. General scheme of the reaction.

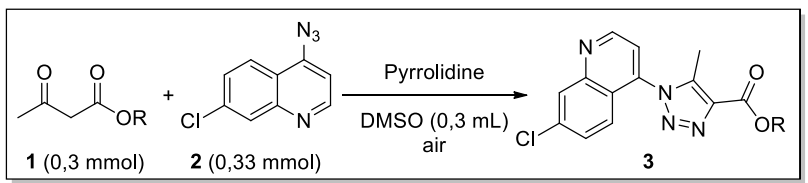

After analyzing the results, we found that the desired product $3 \mathbf{a}$ was obtained in better yield $(90 \%)$, by reacting ethylacetoacetate 1 a $(0.3 \mathrm{mmol})$ with 4-Azido-7-Chloroquinoline 2 (0.33 mmol) in presence of pyrrolidine as organocatalyst (10 mol\%) and DMSO as solvent $(0.3 \mathrm{~mL})$ at room temperature for 24 hours in open flask. After that, under these optimized conditions, we realized some reactions varying the $\beta$-ketoesters $\mathbf{2} \mathbf{a}-\mathbf{k}$ and obtained a range of quinoline-triazoil carboxylates $\mathbf{3 a - k}$ in high yields (Figure 2).

Figure 2. Quinoline-triazoil carboxylates 3a-k synthesized.



\section{CONCLUSION}

In summary, we described the synthesis of molecules containing quinoline and 1,2,3-triazole heterocycles through organocatalytic enamide-azide cycloaddition reaction between $\beta$-ketoesters 1 and 4azido-7-chloroquinoline 2, using for this pyrrolidine as organocatalyst. The quinoline-triazoil carboxylates $\mathbf{3}$ were obtained in high yields under mild reaction conditions.

\section{ACKNOWLEDGEMENTS}

CNPq, CAPES, FAPERGS e FINEP.

\section{REFERENCES}

${ }^{1}$ Grimett, M. R. In Comprehensive Organic Chemistry; Barton, D.; Ollis, D., eds.; Pergamon Press: Reino Unido, 1979.

${ }^{2}$ Danence, L. J. T.; Gao, Y.; Li, M.; Huang, Y.; Wang, J. Chem. Eur. J. 2011, 17, 3584 .

${ }^{3}$ Katritzky, A. R.; Pozharskii, A. F. Handbook of Heterocyclic Chemistry, 2ed; Pergamon: Oxford, 2000.

${ }^{4}$ Musiol, R.; Jampilek, J.; Buchta, V.; Silva, L.; Niedbala, H.; Podeszwa, B.; Palka, A.; Majerz-maniecka, K.; Oleksyn, B.; Polanski, J. Bioorg. Med. Chem., 2006, 14, 359 